\title{
Storage systems for the transition towards active and smart distribution systems
}

\author{
S. Barsali ${ }^{1}$, A. di Donato ${ }^{1}$, R. Giglioli ${ }^{1}$, L. Guidi ${ }^{2}$, E. Pasca ${ }^{2}$, S. Scalari ${ }^{2}$ \\ ${ }^{1}$ Università di Pisa, Dipartimento di sistemi elettrici e automazione, via Diotisalvi, 2, I-56122, PISA, ITALY, e-mail: barsali@dsea.unipi.it \\ ${ }^{2}$ Enel, via Andrea Pisano 120, I-56122, PISA, ITALY, e-mail: sandra.scalari@enel.it
}

\begin{abstract}
The paper presents the criteria adopted for designing a storage system to be used in a distribution grid where several distributed resources exist. The purpose of introducing storage in distribution is to enable the operators to manage the grid as a really active system. A droop based control system has been designed and tested through simulations. The results are currently being used to specify and build a prototype device to be installed in a test facility where Enel will develop a "smart grid".
\end{abstract}

\section{Keywords}

Distributed generation, storage system, inverter control, island operation, renewable sources, smart grids.

\section{Introduction}

Recent developments in the generation scenario and the need for a higher level of power quality, as well as the possibility of exploiting renewable energy sources, are strongly pushing forward the amount of generation directly connected to the distribution level. A lot of opportunities are offered by this continuously increasing share of DG, but the actual exploitation of such possibilities requires a new grid paradigm be developed. New protection systems, new communication tools as well as new management and control methodologies and tools need to be studied, tested and installed [1].

One of the most interesting features of grids with a high share of distributed resources is the possibility of improving the quality of supply to customers by enabling the creation of islands supplied by the locally available generation [2, 3]. Although theoretically feasible from the point of view of the available generation, this option appears often hard to be activated due to the very low, or even null, regulating capability of the generating units. Besides, such units, mainly renewable plants, are often conceived for delivering their power to an infinite power grid and their control systems do not enable working on a small island in parallel to other similar sources. In the most favourable cases a reliable communication system has to be developed for controlling the various units.

It's worth remarking that the grid quality issue strongly affects not only the electricity users but also the distributed producers. A large share of them can sell electricity only when the mains is available and many renewable plants are paid a subsidy for the energy they produce. Often, even a short dip or interruption might force some distributed generators to shut down [18]. Therefore a low quality distribution network results at least in lost revenue and, in several cases, in increased costs for start-up, shut down and plant maintenance.

Storage systems have the opportunity to ease the transition, first into active grids, and then towards really "smart" grids.

Similar problems arise when a large share of renewable energy sources is used to supply a stand-alone system which can either be an island power system or a remote user. In this case, the main issue is the strong variability of the renewable source. A properly designed and controlled storage system enables giving the chance to reach really high level of penetration of renewable sources in standalone systems.

Other power quality issues can be dealt with through storage systems without requiring oversizing the device but simply using proper control methods. Active harmonic filtering and voltage control are typical samples of these services.

Enel has started deploying a wide research project aimed at enabling the development of really active and "smart" grids ${ }^{1}$. One of the main features studied in the first phase of the project, with the cooperation of some Italian Universities, is the use of storage systems. Such systems will be tested through both simulations on a reference grid and by actually installing a properly designed system, first on a laboratory test grid and then on a real distribution grid.

\section{Smart grids}

The vision of a new paradigm for the distribution system has to be realised through several steps which make the final goals being met one after the other. The demand for this transition resides in three main driving factors:

- the evolution of the electricity market from a centralised and monopolistic system towards a deregulated market,

- the increasing demand for a high security and quality of supply,

- the need to increase the share of renewable sources.

This requires that the distribution system changes from a passive, or passively managed, system to a really active system. In fact, although the share of distributed generation connected to the distribution networks already reaches high values in some areas, the present management and control tools and systems make these sources to be operated as a passive load with negative value.

\footnotetext{
${ }^{1}$ Starting from 2007 Enel is financing a 5 year research project named "Smartgrids" in cooperation with six Italian Universities. The aim of the project is to study, develop and test, first in a test facility and then in a real distribution grid, methods, strategies and tools which enable the transition to the new paradigm of distribution system.
} 
The reason for this situation resides in the nature of the distribution grid itself which has been conceived, designed and operated for conveying electricity from the centralised generation and transmission system down to the users.

The real opportunities offered by the distributed resources are so exploited in the least.

The first step to be pursued is to enable the distributed resources to stay connected for supplying a local network, even when the mains trips. This possibility requires that two kinds of stability issues are faced.

\section{A. Electrical stability}

Distributed sources are, today, connected to the network through synchronous machines or asynchronous machines or static converters. It is well known that asynchronous generators on their own are not able to supply a stand alone system for they need an external source for the machine magnetization. A synchronous machine fits all the operating conditions while the choice of the control strategy defines whether an inverter interfaced source can work on a stand alone system. It's clear that the possibility of switching from a parallel to grid operation to a stand alone mode can be actuated only if at least one voltage regulating source exists.

Due to the present structure of the distribution networks, the majority of the distributed resources are not designed to operate on a stand alone system or are not enabled to switch (for inverter interfaced sources) from a parallel to a stand alone mode.

\section{B. Power stability}

There are two main reasons for the share of distributed generation supplying the electric systems is continuously growing. First the possibility for some users to build plants to satisfy their heat and electricity needs at low costs through CHP and to improve the continuity of supply, then the opportunity of exploiting renewable sources which are distributed by nature.

In both cases, the power output from the generators can hardly be controlled by the Distribution System Operator. CHP plants are often managed to fulfil the heat demand while electricity comes out accordingly, as well as some renewable sources can not be controlled at all.

Keeping the balance between generation and demand is likely to be a very hard task even if the generators are suitable for a stand alone operation.

\section{Use of storage systems}

In the first phase of the transition from a passive distribution system to an active and then smart grid, a storage system gives the opportunity of overcoming all the mentioned issues. Obviously, a proper sizing must be adopted.

On the one hand it has the capacity of instantaneously balance the difference between generation and demand, on the other hand, with a proper control strategy, it can enable the stand alone operation of sources interfaced through asynchronous machines and power or current controlled inverters.

\section{Storage system control}

The actual exploitation of all the services a storage system can supply [4] strongly depends on the characteristics of the control system of the inverter [5].

The control scheme which will be adopted for the prototype to be installed in the test facility is based on a frequency and voltage droop scheme.

The basic characteristics of a storage system suitable for operating on an active grid without needing a strong communication support are:

- to operate only on the basis of locally available measurements,

- to be suitable for operating in parallel to the grid, in parallel to other similar devices or distributed generators as well as on a standalone system,

- it should not need to recognize whether the grid is connected or not.

These specifications might appear even too strict if we account the strong communication opportunities offered today for developing distribution management systems. A central control system might be conceived for on-line controlling all the devices installed in the grid. The inverter might therefore be coordinated with the other sources and operated in a master or slave configuration depending on the type and number of sources actually connected. This choice has the main drawback that a failure in the communication system or even a reduction of the bandwidth might cause the system failure.

The solution pursued in this research project is to develop an autonomous system and exploit communication for the optimisation of the operating point. The system is therefore able to operate, within its capability, even without any communication being available.

To this purpose some remarks on the usual inverter control systems are reported.

\section{A. Inverter control systems}

Commercially available inverters can be roughly classified either as current controlled inverter or voltage controlled inverter. The first class is designed for operating in parallel to the mains and can not supply a stand alone system. Voltage controlled inverters can both operate in parallel to the mains (by usually defining the voltage amplitude and phase through a real and reactive power control loop) and on a stand alone system (by working at constant terminal voltage and frequency). Anyway a signal must be available for informing the controller about the operating condition [6]. The parallel operation of an inverter to other sources and even to other inverters is today performed through a centralised control system.

To date, the sole control systems developed for enabling the parallel operation of many inverters without an on-line centralised controller, have been designed for large UPS systems. Frequently, these plants include different size 
UPS devices, often not installed all at once as well as not manufactured by the same company [7, 8, 9]. All the other controllers for commercial inverters are designed according to the previously described classes, including the inverters used for connecting some kinds of generators (PV, fuel cells, some kind of wind turbines) $[10,11]$.

\section{B. Designed control scheme}

In this research project, the control system which will manage the static compensator will be based on a droop scheme as described in Fig. 1. It shows how the amplitude and phase of the inverter voltage are obtained according to real power vs. frequency and reactive power vs. voltage droop characteristics. Maximum power and maximum current loops are also included for limiting the device output within the capability of the components [12].

The response speed of these loops might be too low for protective functions after some events such as a fault on the grid. An inner and faster loop is therefore included for limiting the current peak at a compatible level.

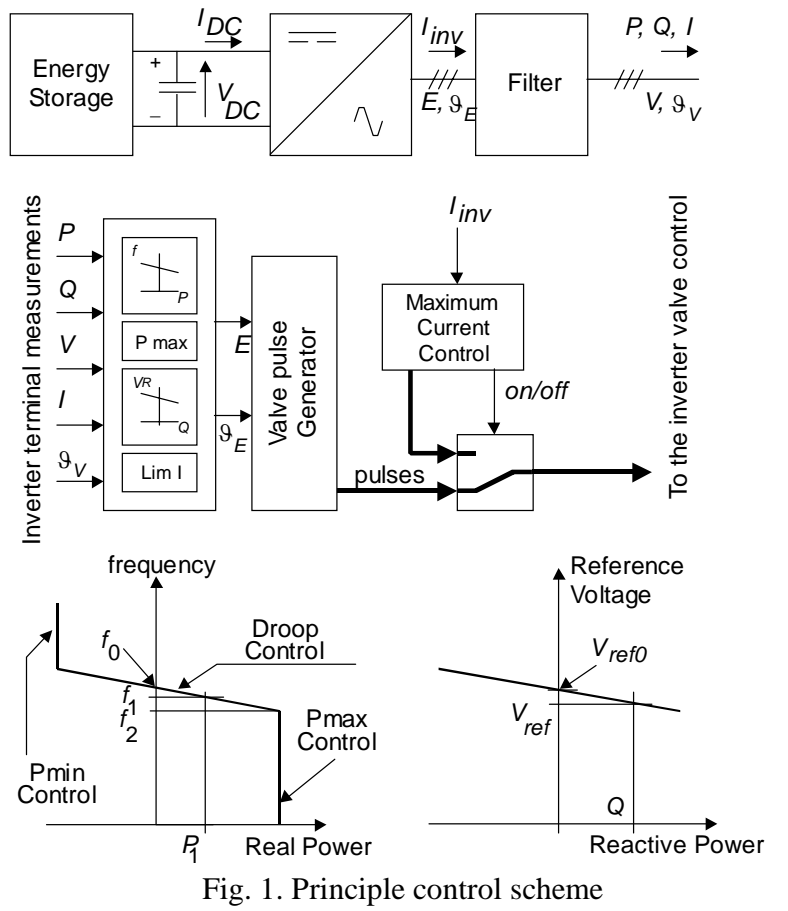

When the inverter operates in parallel with the mains, the frequency is imposed by the mains itself. If the inverter frequency grows, its fundamental phase shift $\vartheta_{E^{-}} \vartheta_{V}$ with respect to the terminal voltage grows as well thus causing the power output to increase. The droop control system will then reduce the inverter frequency thus resynchronising it with the mains.

On a stand-alone system, the frequency will be defined by the load; i.e. to power $P_{1}$ corresponds the frequency $f_{1}$ as shown in Fig. 1.

If several inverters are connected in parallel to supply an isolated grid, they will share the load demand according to their droop characteristics, in the same way as large power plants subject to primary frequency regulation do.
A similar behaviour is obtained on the voltage amplitude side.

When the grid includes some other sources, this control strategy fits all the possible type of generators: synchronous, asynchronous and inverters. As the grid comes to a stand alone configuration the system reaches a stable operating condition, although not optimised. No information is needed from the control centre, and the storage will deliver (within its capability constraints) the power needed for balancing the isolated grid.

The possibility of changing the value of $f_{0}$ or $V_{r f 0}$ on the two droop characteristics enables activating a kind of secondary control which operates within some cycles of the fundamental (200-300ms). These reference values will be defined by the distribution system operator for performing some compensation functions during the grid connected mode and an optimisation of the operating point in the stand alone mode. The secondary control will then be also used for keeping frequency and voltage within quality standards.

\section{Development of a test facility}

The first phase of the research project is being devoted to deploying a test facility for emulating the behaviour of a real, although limited in the number of components, medium voltage distribution network. The test facility will include different kinds of distributed generators (some actually installed and others emulated through an AC/DC/AC conversion system) and a 1MW, 1MWh battery storage system.

A Distribution Management System will be developed for coordinating all the sources. The first step will be enabling the stand alone operation of the system and the automatic switch from grid connected to stand alone mode operation, without changing the control strategies of the other sources connected to the network. To this purpose, the storage system will operate as described above for keeping generation and demand balanced. Communication systems will be used for rearranging the power sharing among the sources by changing the set points of each source control system.

\section{Model and simulations}

The operation of the storage system has been checked through simulations on a grid which includes synchronous and asynchronous generators as well as some loads. The most common sequence of events which occur on a medium voltage distribution network is the loss of the mains due to fault clearing sequences. The fault itself is just detected by the protection system but does not affect the network operation. In Italy, and in several other systems, medium voltage distribution networks are isolated neutral or compensated neutral systems; single phase fault currents are thus very low.

The reference scheme of the system is shown in Fig. 2. To check the operation with both synchronous and 
asynchronous generators, different sizes are hypothesised for the various components. The compensator is rated $1 \mathrm{MW}$ in all the tested condition. A model of the whole compensator has been developed and used for testing the control algorithm $[13,14]$.

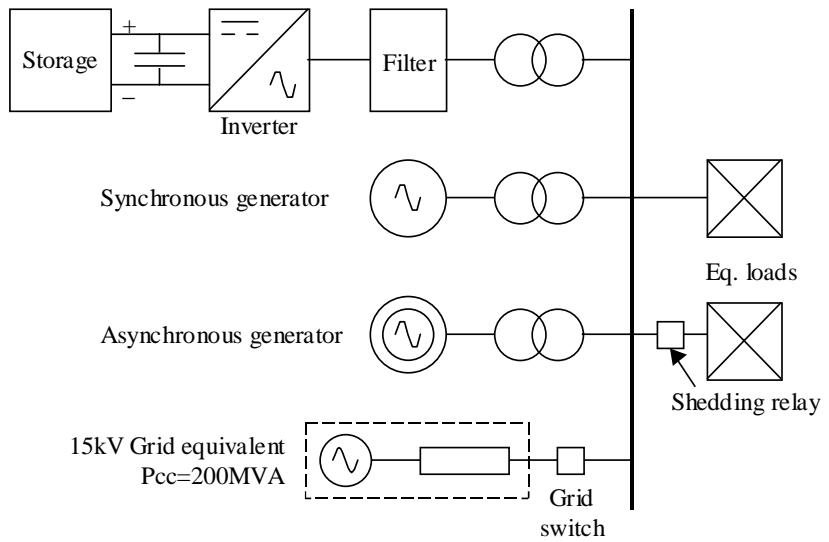

Fig. 2. One-line diagram of the test system

\section{A. Operation of the compensator alone}

In some areas the demand for high quality standards might be fulfilled by installing a storage system to be used for several services during the parallel to grid operation and for supplying local loads as the grid trips, although no distributed generators exist in the area.

The following pictures refer to a $1 \mathrm{MW}$ load and a 1MVA compensator. The transient reported shows the tripping of the mains at $\mathrm{t}=0.7 \mathrm{~s}$, the re-synchronisation at $\mathrm{t}=1.7 \mathrm{~s}$, a step in the voltage reference $V_{r f 0}$ at $\mathrm{t}=2.5 \mathrm{~s}$ and a step in the frequency reference $f_{0}$ at $\mathrm{t}=3.5 \mathrm{~s}$.

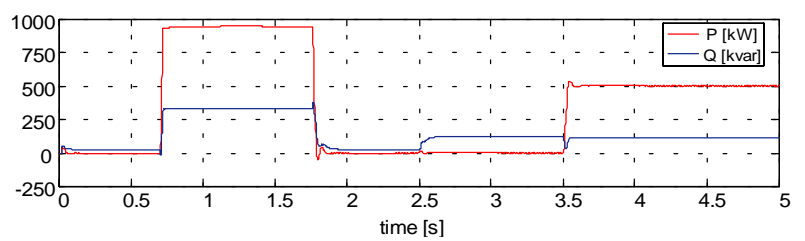

Fig. 3. Inverter real and reactive power

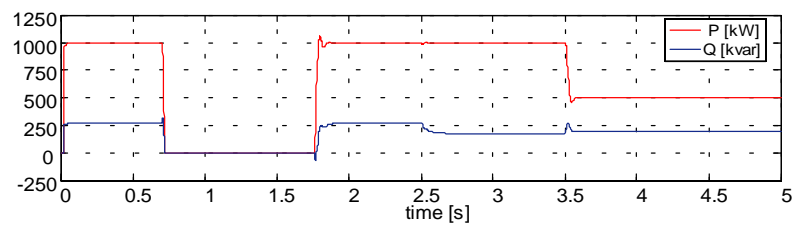

Fig. 4. Mains supplied real and reactive power.

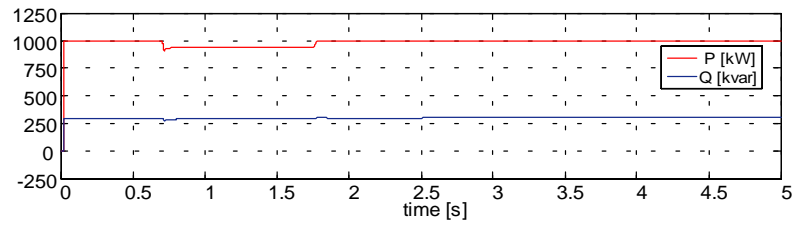

Fig. 5. Load real and reactive power

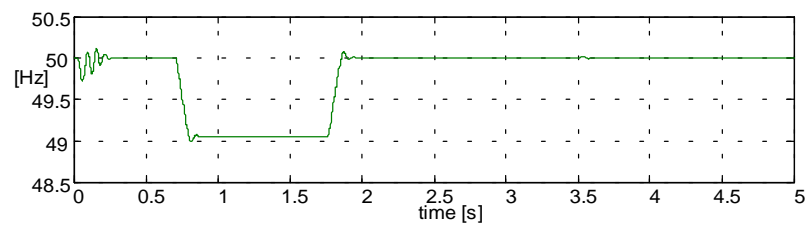

Fig. 6. Inverter terminal frequency

The graphs show how the compensator is able to quickly replace the supply from the grid. It sets the frequency at $49 \mathrm{~Hz}$ for the frequency droop is $2 \%$ and the demand from the load is the rated compensator power. The adjustments of the voltage and frequency set-points after the resynchronisation show how the real and reactive power flows can be effectively controlled.

\section{B. Operation with a synchronous generator}

Synchronous generators are usually installed in reciprocating engine based systems. Many small CHP plants are based on these units and several synchronous generators are therefore likely to be connected on an active distribution system.

As already mentioned, CHP plants usually operate in a thermal load following mode. Their electricity output can therefore be hardly controlled. The first simulation (Fig. 7 to Fig. 11) hypothesises that the prime mover output does not change during the transient.

The synchronous generator is rated 2.5MVA, 2MW, and the total load sums $3.4 \mathrm{MW}$ and $1.7 \mathrm{Mvar}$. A small contribute comes from the 200kVA asynchronous generator. At $\mathrm{t}=2 \mathrm{~s}$ the grid trips and the compensator starts supplying power up to its rated value (1MW). Roughly $400 \mathrm{~kW}$ remain unbalanced and the frequency on the grid continues to decrease until $600 \mathrm{~kW}$ of load are shed when the frequency reaches $48 \mathrm{~Hz}$. The output from the compensator thus returns below the maximum value and the frequency is restored at $49.2 \mathrm{~Hz}$. As the grid conditions enable re-closing the parallel switch, the isolated system is reconnected to the mains at $\mathrm{t}=4.3 \mathrm{~s}$.

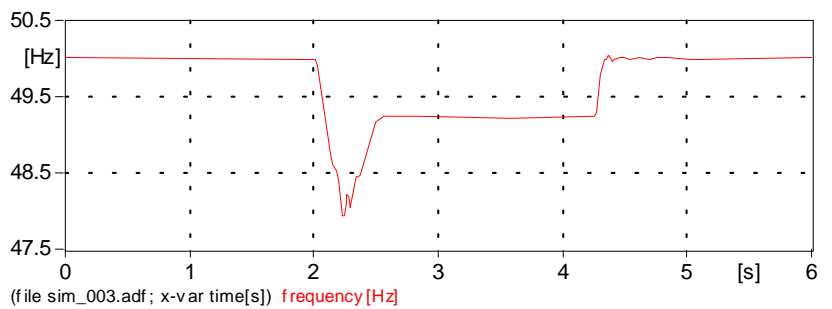

Fig. 7 System frequency

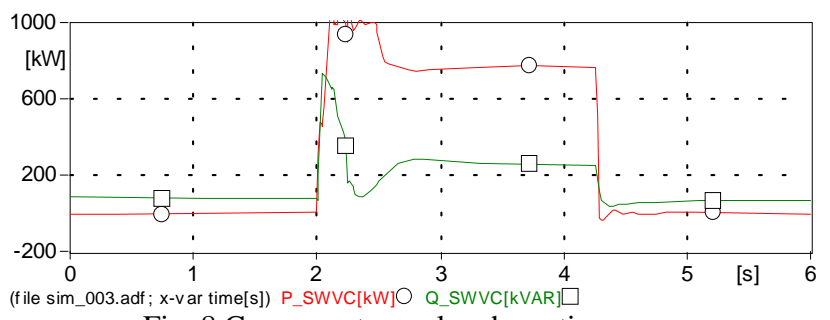

Fig. 8 Compensator real and reactive power 


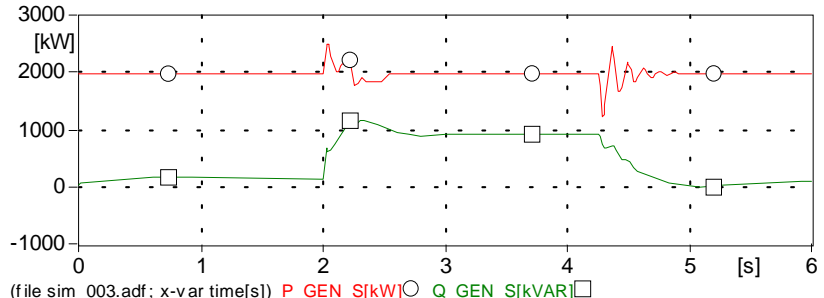

Fig. 9 Synchronous generator real and reactive power

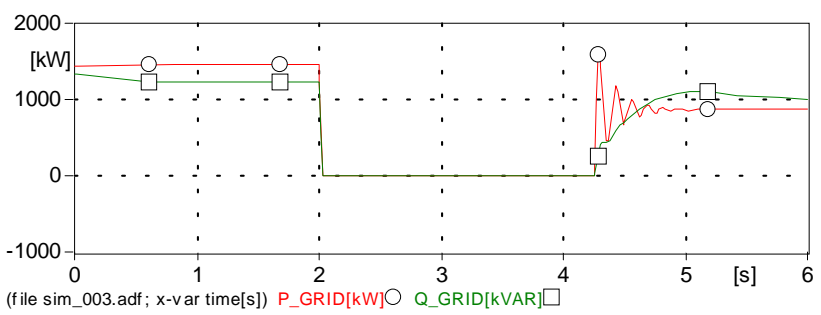

Fig. 10 Grid real and reactive power

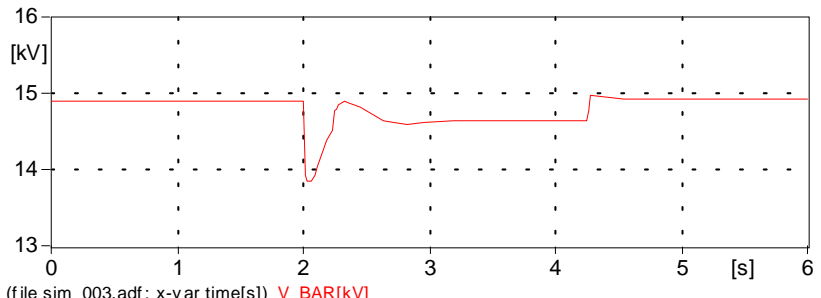

Fig. 11 Busbar voltage

\section{Operation with an asynchronous generator}

Asynchronous generators are a rather common interface for wind turbines. This kind of units shows two main issues to be solved for enabling a stand alone mode operation. First the asynchronous generator needs an external source for the magnetisation, and then the power fluctuation from the wind must be balanced. The power output from wind continuously changes both for the wind speed continuously varies and also for the blade passes before the tower [17]. The first issue has a relatively slow dynamic, while the latter happens with a frequency around $1 \mathrm{~Hz}$ (for a three-bladed 20rpm machine). Although in large wind farms the various turbines compensate with each other and the largest units have now adopted variable speed solutions which mitigate this effect, in distribution networks it is likely to be a major issue.

Two simulations have therefore been carried out, the first with a constant torque (Fig. 12 to Fig. 16) and the second with a $1 \mathrm{~Hz}$ pulsating torque (Fig. 17 to Fig. 21). The wind turbine is supposed to have 700kvar capacitance installed on board for compensating part of the reactive power demand from the generator. In both the simulations the sequence of events includes the grid trip at $t=1 \mathrm{~s}$, a ramp change in the compensator voltage set-point from $\mathrm{t}=3 \mathrm{~s}$ to $\mathrm{t}=4 \mathrm{~s}$ and the resynchronisation to the grid at $\mathrm{t}=5.1 \mathrm{~s}$, as soon as the parallel conditions are met.

The first simulation shows how the compensator enables the asynchronous generator to supply an isolated system. It supplies the reactive power demanded by the asynchronous machine as well as the real power unbalance.

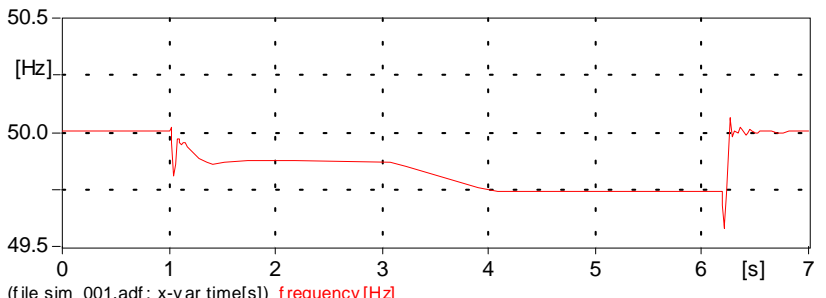

Fig. 12 System frequency

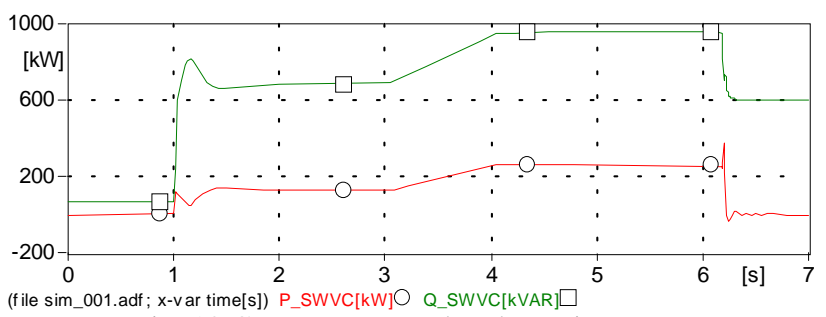

Fig. 13 Compensator real and reactive power

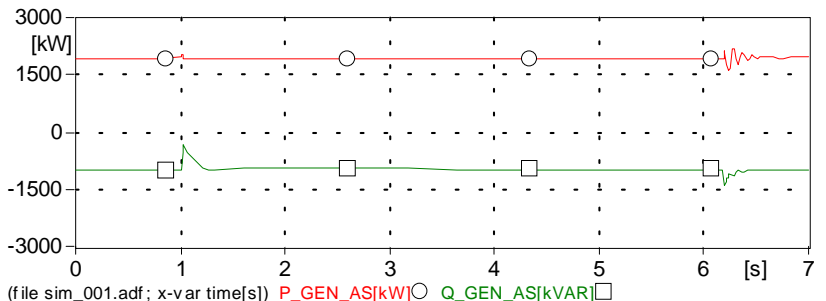

Fig. 14 Asynchronous generator real and reactive power

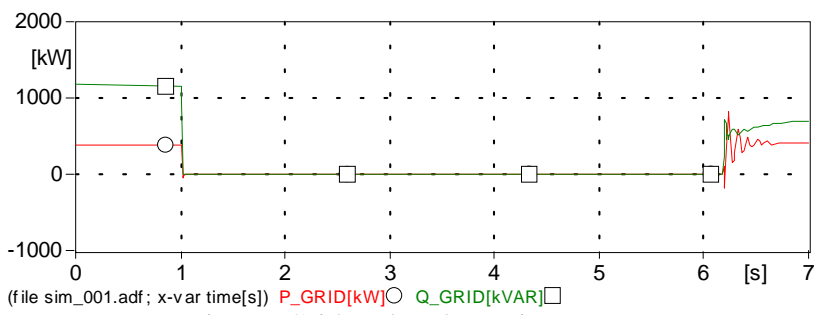

Fig. 15 Grid real and reactive power

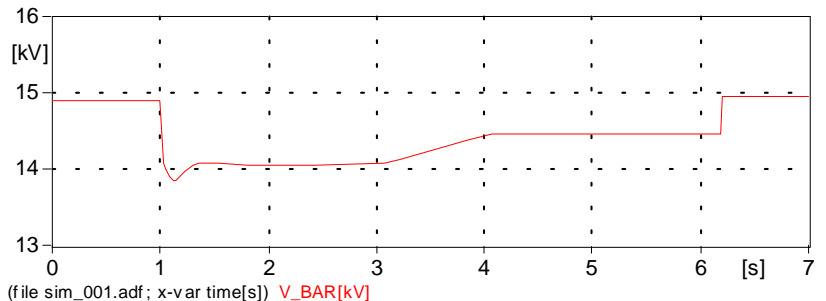

Fig. 16 Busbar voltage

The second simulation shows the prompt action of the storage system in compensating the quick fluctuations of the wind turbine power output. The use of the storage system enables therefore developing isolated systems supplied by a large share of renewable sources. The simulated case is one of the worse possible configuration: a fluctuating source connected through an asynchronous machine. 


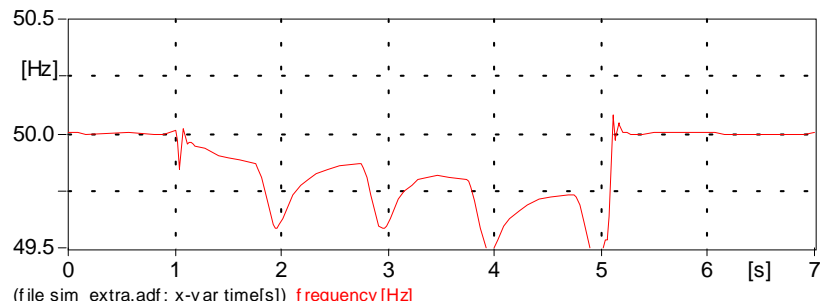

Fig. 17 System frequency

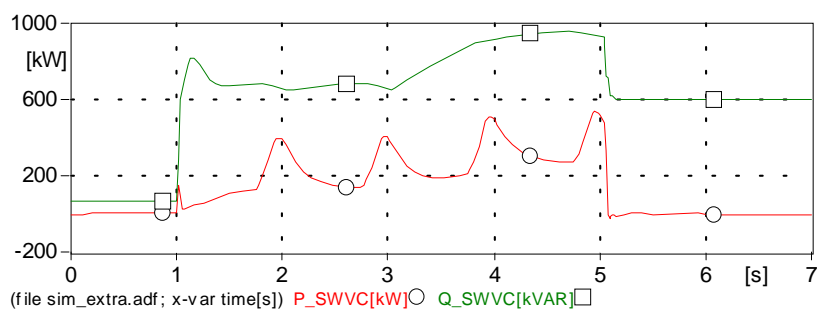

Fig. 18 Compensator real and reactive power

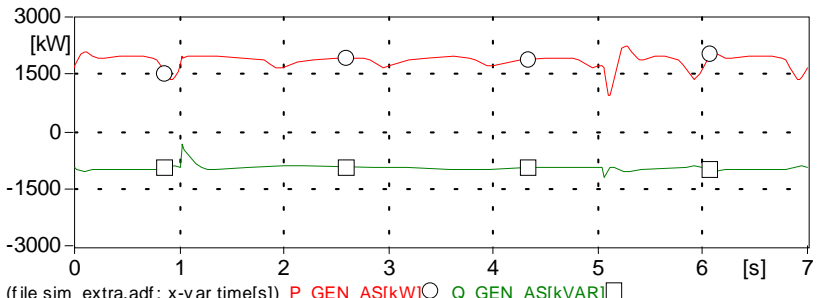

Fig. 19 Asynchronous generator real and reactive power

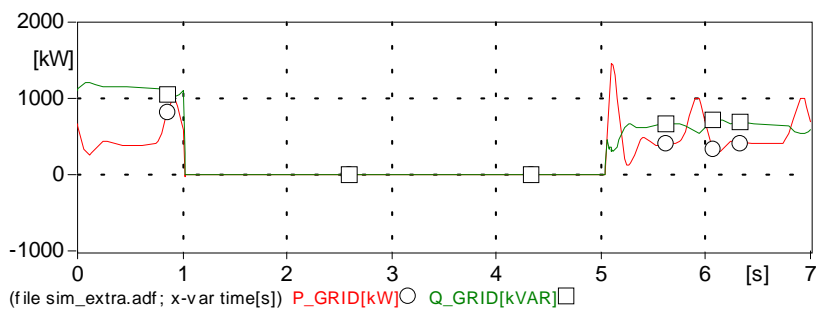

Fig. 20 Grid real and reactive power

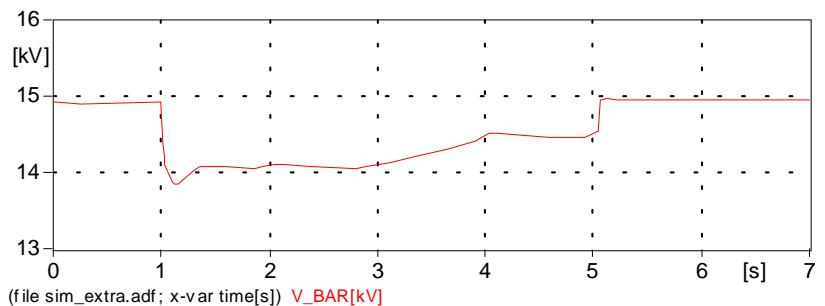

Fig. 21 Busbar voltage

\section{Remarks}

The results obtained in the first phase of the research activity deployed jointly with Enel show the possibility of developing a storage system suitable for improving the quality of supply on a grid. The storage system can be profitably used for compensating the low regulating capability of the existing sources. They also show how a droop control of voltage and frequency enables the island operation although the control systems of the existing generators are not properly designed to this purpose.

The paper finally showed how the droop control method appears to be an effective solution also for interfacing a storage system to a stand-alone system with a large share of renewable sources.

\section{References}

[1] R. C. Dugan, T. F. McDermott, G. J. Ball, "Planning for Distributed Generation”, IEEE Industry Application Magazine, March-April 2001.

[2] B. Lasseter, "Role of Distributed Generation in Reinforcing the Critical Electric Power Infrastructure” IEEE-PES Winter Meeting 2001, Columbus, OH (USA) January 28-February 1, 2001

[3] S. Barsali, G. Celli, M. Ceraolo, R. Giglioli, P. Pelacchi, F. Pilo, "Operating and planning issues of distribution grids containing diffuse generation" CIRED 2001, Amsterdam, The Netherlands, June 18-21, 2001

[4] T. Moore, "Emerging Markets for Distributed Resources", EPRI JOURNAL March-April 1998

[5] R.H.Lasseter, "MicroGrids" IEEE-PES Winter Meeting, New York, NY, USA, January 27-31, 2002

[6] S.R.Wall, "Performance of inverter interfaced distributed generation”, IEEE PES Transmission and Distribution Conference and Exposition, Atlanta, GA, USA, October 28-November 2, 2001

[7] M.C.Chandorkar, D.M.Divan, R.Adapa, "Control of parallel connected inverters in standalone ac supply systems" IEEE Transactions on Industry Applications, vol. 29 n¹ Jan/Feb 1993

[8] M.C.Chandorkar, M.D.Divan, B.Banerjee, "Control of distributed UPS systems” Power Electronics Specialists Conference 1994, Taipei, Taiwan, June 20-25, 1994

[9] A.Tuladhar, H.Jin, T.Unger, K.Mauch, "Parallel operation of single phase inverter modules with no control interconnections" Applied Power Electronics Conference and Exposition 1997, Atlanta, GA, USA, February 23-27, 1997

[10] M. Etezadi-Amoli, K. Chroma, "Electrical Performance Characteristics of a New Micro-Turbine Generator" IEEE-PES Winter Meeting 2001, Columbus, OH (USA) January 28-February 1, 2001

[11] S.Banetta, S.Barsali, M.Ceraolo, R.Giglioli, P.Bolognesi, "Microturbine cogeneration units", UTET: Power technology, Vol. 3, N4, July 2002

[12] S. Barsali, M.Ceraolo, P.Pelacchi, D.Poli, "Control techniques of dispersed generators to improve the continuity of electricity supply”, IEEE PES Winter Meeting, New York, NY, USA, January 27-31, 2002

[13] M.Ceraolo, "Dynamical models of lead-acid batteries" IEEE Transactions on Power Systems, Vol. 15, Issue 4, November 2000

[14] S.Barsali, M.Ceraolo, "Dynamical Models of Lead-Acid Batteries: implementation issues" IEEE Transactions on Energy Conversion Vol. 17, Issue 1, March 2002

[15] S. Roy, O.P. Malik, G.S. Hope, "An adaptive control scheme for speed control of diesel driven power-plants", IEEE Transactions on Energy Conversion, Vol. 6, No. 4, December 1991

[16] L. Bryans, G.R. Bryans, B. Fox, "Studies and progress towards intermittence management on a small system”, CIGRÉ Symposium "Power Systems with Dispersed Generation" Athens, Greece, April 13-16, 2005

[17] T. Thiringer, J. Dahlberg, "Periodic pulsations from a three-bladed wind turbine”, IEEE Transactions on Energy Conversion Vol. 16, Issue 2, June 2001

[18] A. I. Estanqueiro, J. O. Tande, J. A. Peças Lopes, “Assessment of power quality characteristics of wind farms”, IEEE PES General Meeting, Tampa, FL, USA, June 24-28, 2007. 